\title{
Prevalence and Risk Factors for Acute Coronary Syndrome Among Sudanese Individuals With Diabetes: A Population- Based Study
}

\author{
Mohamed H. Ahmeda, g, Heitham Awadallab ${ }^{\mathrm{b}}$, Wadie M. Elmadhoun ${ }^{\mathrm{c}}$, \\ Mugtaba Osman ${ }^{\mathrm{d}}$, Sufian K. Noor ${ }^{\mathrm{e}}$, Ahmed O. Almobarak ${ }^{\mathrm{f}}$
}

\begin{abstract}
Background: Acute coronary syndrome (ACS) is common with diabetes. The aim of this study was to establish prevalence and risk factors for ACS among Sudanese individuals with diabetes mellitus (DM).

Methods: A descriptive cross-sectional study was conducted in Khartoum State and Atabra (North of Sudan). The data collection was performed through pretested questionnaire, in addition to measurement of lipid profile and $\mathrm{HbAlc}$.

Results: Among the 496 respondents, 234 (48.4\%) were males and only 15 of them had ACS, while 255 (51.6\%) were females and 12 had ACS. Therefore, the prevalence of ACS was $5.44 \%$ (95\% confidence interval $(\mathrm{CI}): 3.45-7.44 \%$ ). The unadjusted risk factors for ACS were age $(\mathrm{P}=0.0008864)$, duration of $\mathrm{DM}(\mathrm{P}=0.01105)$ and presence of hypertension ( $\mathrm{P}=0.0006021)$. The presence of albuminuria, gender, and body mass index (BMI) was not associated with ACS. In addition, parameters like $\mathrm{HbA1c}$, high-density lipoprotein (HDL), triglyceride and low-density cholesterol (LDL) were also not associated with ACS. Logistic regression analysis showed that duration of diabetes (odds ratio $(\mathrm{OR})$ for below 5 years' history of $\mathrm{DM}=0.175$ (95\% CI for OR: $0.180-0.835), \mathrm{P}=0.04051)$ and hypertension $(\mathrm{OR}$
\end{abstract}

Manuscript submitted September 24, 2017, accepted October 4, 2017

a Department of Medicine and HIV Metabolic Clinic, Milton Keynes University Hospital NHS Foundation Trust, Eaglestone, Milton Keynes, Buckinghamshire, UK

${ }^{b}$ Department of Community Medicine, Faculty of Medicine, University of Khartoum, Sudan

'Department of Pathology, Faculty of Medicine and Health Sciences, Nile Valley University, Sudan

${ }^{\mathrm{d}}$ Department of Psychiatry, Royal College of Surgeons in Ireland, Republic of Ireland

eDepartment of Medicine, Faculty of Medicine and Health Sciences, Nile Valley University, Sudan

fDepartment of Pathology, Faculty of Medicine, University of Medical Sciences and Technology, Khartoum, Sudan

gCorresponding Author: Mohamed H. Ahmed, Department of Medicine and HIV Metabolic Clinic, Milton Keynes University Hospital NHS Foundation Trust, Eaglestone, Milton Keynes, Buckinghamshire, UK.

Email: elziber@yahoo.com

doi: https://doi.org/10.14740/cr616w

\author{
$=2.462(95 \% \mathrm{CI}$ for OR: $1.007-6.500), \mathrm{P}=0.039)$ were absolute risk \\ factors for ACS.
}

Conclusion: The prevalence of ACS is estimated to be $5.44 \%$. ACS in Sudanese individuals with DM was associated with hypertension, increase in age and increase in duration of DM.

Keywords: Acute coronary syndrome; Sudan; Diabetes mellitus

\section{Introduction}

Sudan, as one of the largest countries in Africa, has also experienced an increase in the prevalence of the non-communicable disease in the same scale as other African countries [1]. For instance, Noor et al have shown that the burden of non-communicable diseases was found to exceed that of communicable diseases among patients admitted to medical wards at main teaching hospital in the north of Sudan [1]. This increase in non-communicable disease was also associated with an increase in the prevalence of diabetes. Elmadhoun et al showed that the prevalence of diabetes mellitus (DM) in urban areas in north of Sudan has increased to $19 \%$ in 2015, while the prevalence in 1995 was estimated to be around 7\% [2]. Their study showed that increasing age, a family history of DM, central obesity, abnormal body mass index (BMI), and hypertension were significant risk factors for DM. Importantly, Noor et al showed that the prevalence of DM in rural areas in Sudan was estimated to be $2.5 \%$ in 2015 and this was similar to the prevalence in 1996 which was $2.5 \%$ [3]. This difference in prevalence of DM between rural and urban areas may be attributed in part to the increase in prevalence of obesity. Ahmed et al have shown in a large population study of 7,239 Sudanese individuals that the prevalence of obesity was $21.2 \%$. Furthermore, obesity and central obesity have a higher prevalence among Sudanese women and are associated with DM and hypertension [4]. Importantly, the prevalence of obesity among Sudanese individuals with DM was estimated to be $24.5 \%$ and overweight was $39.9 \%$, and the prevalence was more in women than in men and associated with hypertension [5]. Optimization of DM control will be a big challenge for health authorities in Sudan, as $85 \%$ of individuals with type $2 \mathrm{DM}$ have Hb1Ac of more than 7\% [6]. This can 
also be attributed to the increase in prevalence of fatty liver and insulin resistance. For instance, Almobarak et al showed that the prevalence of fatty liver among Sudanese individuals with type 2 DM was around $50 \%$, while the prevalence in population without DM was estimated to be around $20 \%$ [7, 8]. Another factor for poor DM control may be attributed to low physical activity, especially in women [9]. Therefore, it is plausible to suggest that Sudanese individuals with DM are likely to encounter DM complications. Awadalla et al showed that the prevalence of neuropathy, hypertension and high cholesterol was $68 \%, 39 \%$ and $59.9 \%$, respectively. They attributed the presence of DM complications to duration of DM and living in urban areas [10]. Almobarak et al showed that the prevalence of DM foot ulcer was around $18 \%$ and duration of DM was an absolute risk factor [11]. Furthermore, retinopathy prevalence was around $86 \%$ and duration of DM and hypertension were absolute risk factors [12]. Ahmed et al showed that the presence of retinopathy can be associated with nephropathy in Sudanese individuals with DM and hypertension can be a risk factor [13]. In view of the increase in prevalence of DM, DM complications and obesity, the aim of this study was to assess prevalence and risk factors for acute coronary syndrome (ACS) among Sudanese individuals with DM.

\section{Methods}

\section{Study design}

A descriptive cross-sectional, hospital-based study was carried out in Khartoum and Atbara, Sudan, between September and December 2015.

\section{Study population and sampling}

A total of 496 individuals with DM were enrolled in this study.

\section{Data collection}

The WHO stepwise approach for non-communicable diseases surveillance was used for data collection. The approach had three levels: a questionnaire to gather demographic and behavioral information; physical measurements including anthropometric and blood pressure; and biochemical tests. The variables collected were: demographic and background factors including age, gender, smoking, alcohol intake, DM duration and medications, and other co-morbidities, such as heart failure. Height and weight were assessed to calculate BMI. Blood indices estimated were: HbA1c, cholesterol and triglycerides levels.

\section{Laboratory measures}

Blood sample and urine sample were collected from each participant, who was willing to participate in the study and gave their verbal consent. The collection was done by a skilled laboratorist in sterilized condition. Blood samples were separated in two vacuum tubes: ethylenediaminetetraacetic acid (EDTA) reagent for $\mathrm{HbA} 1 \mathrm{c}$ and lithium reagent for renal function test (RFT) and lipid profile. The laboratory tests were carried out using Cobas c 111 analyzer for sample analysis.

\section{Data analysis}

Data were cleaned, organized, coded and entered in master sheet and analysed using R-statistical software version 3.4.1.. The main variables analyzed were age, sex, BMI, blood glucose level, retinopathy, neuropathy, albuminuria, blood pressure, a family history of DM, duration of DM, cholesterol, triglyceride and $\mathrm{HbAlc}$. Chi-squared test was used to test for significance between proportions. P-value $<0.05$ was considered statistically significant. Logistic regression analysis was used to establish absolute risk factors.

\section{Ethical approval}

Verbal consent was obtained from each participant prior to enrolment. The following information was given during data collection to ensure they had the information needed to make the informed consent: participation was optional; there would be no penalty for refusal. A complete description of the aims and procedures of the study was clarified; potential benefits and risks were explained, and assurance of confidentiality of any information was guaranteed. Any other additional information requested by participants was provided during data collection. All individuals found to have a high blood pressure, or any other medical condition were referred, according to their will, to a physician for further management. All information obtained was kept confidential. All patients attending the physicians clinic at the time of study were offered free of charge investigations and medications, and no additional financial burdens were added to participants. An ethical clearance of the research was obtained from the Ethical Committee of the Faculty of Medicine, University of Medical Science and Technology, Khartoum, Sudan (IRB No. 00008867).

\section{Results}

\section{Sociodemographic variables}

The study is a retrospective observational analysis of $496 \mathrm{Su}-$ danese patients with an established diagnosis of DM. There were 27 patients who developed ACS. Therefore, the prevalence of ACS was 5.44\% (95\% confidence interval (CI): 3.45 $7.44 \%)$. Of the participants in the study, $257(51.8 \%)$ were females, whereas $239(48.2 \%)$ were males. Among the 27 participants with ACS, 12 were females (ACS prevalence $=$ $4.7 \%$ ) and 15 were males (ACS prevalence $=6.3 \%$ ). However, this association between males and increased risk of ischemic heart disease (IHD) was not statistically significant (X-squared 
Table 1. Characteristics of the Respondents According to Diagnosis of ACS

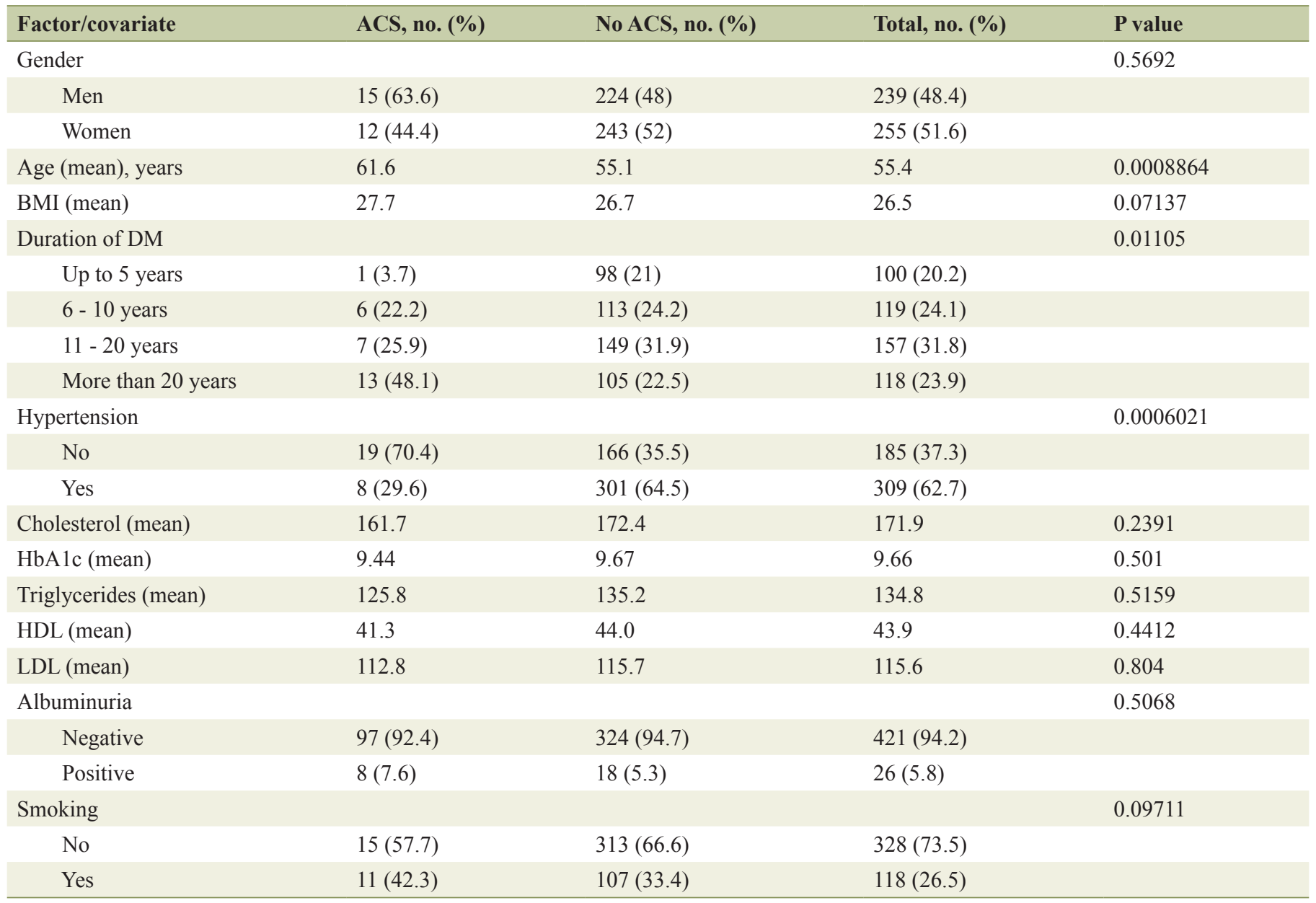

$P$ values $<0.05$ are considered significant; Pearson Chi-squared and $t$-tests were used to check for significance between variables.

$=0.3241$, degrees of freedom $(\mathrm{df})=1, \mathrm{P}=0.5692)$. The mean age was 55.4 years (standard deviation $(\mathrm{SD})=12.5$ years, range between 20 and 90 years). The median age was 55.5 years. The mean age for ACS group was 61.6 years, whereas the mean age for those with no ACS was 55.1 years. This 6.5year difference was statistically significant $(\mathrm{t}=3.657 \mathrm{df}=$ 32.78, $\mathrm{P}=0.0008864)$. The mean $\mathrm{BMI}$ was $26.8(\mathrm{SD}=6.73$, range between 14.06 and 96). The median BMI was 26.5. The mean BMI for IHD group was 27.7, whereas the mean BMI for those with no IHD was 26.7. This 1-unit difference was not statistically significant $(\mathrm{W}=4278.5, \mathrm{P}=0.07137)$. In addition, albuminuria and gender were not associated with ACS. Furthermore, parameters like $\mathrm{HbA1c}$, high-density lipoprotein (HDL), triglyceride and low-density cholesterol (LDL) were also not associated with ACS (Table 1).

\section{Duration of DM}

Out of the total 27 participants with ACS, 13 (prevalence = $11 \%$ ) were living with DM for more than 20 years, seven (prevalence $=4.5 \%$ ) were living with DM for $11-20$ year, and six (prevalence $=5 \%$ ) were living with DM for 6 - 10 years, with one (prevalence $=1 \%$ ) from the under 5 years' duration group getting the ACS. This association between the duration of DM and increased risk of ACS was statistically significant $(\mathrm{X}$-squared $=11.129, \mathrm{df}=3, \mathrm{P}=0.01105)$.

\section{Hypertension}

Among the 27 participants with ACS, there were 19 with hypertension diagnosis (prevalence $=10.3 \%$ ) and eight without (prevalence $=2.6 \%$ ). This unadjusted association between hypertension diagnosis and increased risk of IHD was statistically significant $(\mathrm{X}$-squared $=11.7694, \mathrm{df}=1, \mathrm{P}=0.0006021)$.

\section{Smoking}

Out of the total 27 participants with IHD, there were 11 with history of smoking (prevalence $=9.3 \%$ ) and 15 without (prevalence $=4.6 \%$ ). However, this association between history of smoking and increased risk of ACS was not statistically sig- 
Table 2. Logistic Regression Analysis for Risk Factors of ACS

\begin{tabular}{lllll}
\hline Factor/covariate & OR & Lower 95\% CI & Upper 95\% CI & P value \\
\hline Male gender & 0.5166922 & 0.1375752 & 1.6081059 & 0.25065 \\
Age & 1.0299497 & 0.9837644 & 1.0805835 & 0.18085 \\
BMI & 1.0320679 & 0.9500168 & 1.0827273 & 0.24934 \\
Duration of DM & 0.1751397 & 0.1802962 & 0.8354782 & 0.04051 \\
Hypertension & 2.4620328 & 1.006920 & 6.5000341 & 0.03916 \\
Cholesterol & 1.0037601 & 0.9932443 & 1.0114327 & 0.36075 \\
HbA1c & 0.9397261 & 0.7582192 & 1.1143376 & 0.47802 \\
Triglycerides & 0.9987686 & 0.9918043 & 1.0041398 & 0.65345 \\
HDL & 1.0041865 & 0.9737831 & 1.0289004 & 0.74243 \\
LDL & 1.0012480 & 0.9927317 & 1.0099615 & 0.75116 \\
Smoking & 2.4882621 & 0.7201396 & 9.6310948 & 0.13486 \\
Albuminuria & 1.0368389 & 0.3540358 & 2.7341348 & 0.94096 \\
\hline
\end{tabular}

$P$ values $<0.05$ are considered significant; duration of DM and hypertension were absolute risk factors for ACS.

nificant $(X$-squared $=2.7523, \mathrm{df}=1, \mathrm{P}=0.09711)$.

\section{Logistic regression analysis}

Utilizing the full logistic regression model that adjusts for all risk factors for ACS simultaneously, this was significant for the variables of duration of DM (OR for below 5 years' history of $\mathrm{DM}=0.175(95 \% \mathrm{CI}$ for OR: $0.180-0.835), \mathrm{P}=0.04051)$ and hypertension $(\mathrm{OR}=2.462(95 \% \mathrm{CI}$ for $\mathrm{OR}: 1.007-6.500)$, $\mathrm{P}=0.039$ ) (Table 2).

\section{Discussion}

Khalil et al showed that coronary event rate for men and women was 112/100,000 in Khartoum in 1989 [14]. Khalil et al used the diagnostic and classification criteria of the World Health Organization Monitoring of Trends and Determinants in Cardiovascular Disease (MONICA) project. In Egypt, the overall prevalence of coronary heart disease was estimated to be $8.3 \%$ and this prevalence was thought to be higher in women $(8.9 \%)$ relative to men $(8.0 \%)$ [15]. The prevalence of ACS in Saudi Arabia was thought to be around 6\% [16], while in Lebanon, this was estimated to be $13 \%$ [17]. Our study showed that the prevalence of ACS was 5.44\% among individuals with DM. Hertz et al have summarized finding of studies (including a total of 92,378 in five different countries) in prevalence of ACS in sub-Saharan Africa (SSA), and their data showed that the prevalence of acute myocardial infarction ranged from $0.1 \%$ to $10.4 \%$ [18]. Despite such low prevalence of ACS in sub-Saharan Africa, Onen predicted an increase in prevalence of ACS by 2030 due to the rising prevalence of risk factors, especially hypertension, DM, overweight, obesity, physical inactivity, increased tobacco use and dyslipidemia. The possible estimation that age-standardized mortality rates for IHD will rise by $70 \%$ in African men and $74 \%$ in women by 2030 [19]. In Sudan, diagnosis of ACS among individuals with DM can be associated with high risk of morbidity and mortality. For instance, among 67 individuals with DM who died in Hospital in Khartoum, $10 \%$ of death was attributed to myocardial infarction [20]. Onen and Hertz et al in their systematic reviews described the problem of insufficient population-based data and the need to establish registries for ACS using common diagnostic criteria. This is urgently needed in sub-Saharan Africa as this will help not only with establishing surveillance studies that capture the broad and diverse population with acute myocardial infarction, but also guiding prevention and treatment strategies for ACS [18, 19]. Therefore, one limitation of this study was that the diagnosis of ACS was reported by the patients during interview. This is unlikely to represent recall bias as diagnosis of ACS is major one and is unlikely to be forgotten or mixed with other condition.

The unadjusted risk factors for ACS in this study were age $(\mathrm{P}=0.0008864)$, duration of $\mathrm{DM}(\mathrm{P}=0.01105)$ and presence of hypertension ( $\mathrm{P}=0.0006021)$. However, logistic regression analysis showed hypertension and duration of DM are absolute risk factors. Data from the Sudan Household Survey (SHHS) 2006 showed that the prevalence of heart disease in Sudan is around 2.5\% (hypertensive heart disease (HHD), rheumatic heart disease (RHD), IHD and cardiomyopathy constitute more than $80 \%$ of cardiovascular disease (CVD) in Sudan). High prevalence of risk factors for CVD was also recorded. For instance, physical activity, obesity, hypertension, hypercholesterolemia, DM and smoking were estimated to be around $86.8 \%, 53.9 \%, 23.6 \%, 19.8 \%, 19.2 \%$ and $12 \%$, respectively in the SHHS. Hypertension was associated with poor control and a high prevalence of target-organ damage [21]. High prevalence of hypertension in different regions and ethnic groups in Sudan was found to be high. For instance, in urban population in North of Sudan, the prevalence of hypertension was estimated to be more than $30 \%$ [22]. While in rural population, the prevalence was estimated to be $15-38 \%$ in Sudan [23, 24]. Importantly, the prevalence of hypertension in Nubia ethnic population in South of Sudan living in the North of Sudan was estimated to be around 50\% [25]. 
Importantly, several studies indicated that DM emerged as a strikingly common correlate to hypertension [26-28]. In rural and urban areas in Sudan, hypertension was found to be significantly associated with diabetes $[22,23]$. Hypertension will be a big challenge for health authorities, not only in Sudan but also in all countries in SSA $[29,30]$. This is likely due to high prevalence of hypertension and the shared metabolic risk factors with DM. Therefore, it is important not to underestimate socio-economic implications. Strategies are urgently needed in Sudan to tackle the problems of under-diagnosis, low levels of control and need for tight blood pressure control, especially in individuals with DM.

In this study, duration of DM was also found to be an absolute risk factor for ACS. Awadalla et al have shown that majority of DM complications are associated with duration of $\mathrm{DM}$ and living in urban area [10]. Almobarak et al have shown duration of DM is also an absolute risk factor for DM foot ulceration [11]. Furthermore, duration of DM and hypertension were absolute risk factors for retinopathy in Sudan [12].

This study is not without limitations. The cross-sectional design may not allow for generalization of the results to the whole population. The role of genetic and nutritional factors and link with ACS were not investigated. Despite these limitations, this study is novel, important and pioneer in drawing attention of health professions and health policy makers to consider strategies to prevent mange and treat risk factors that lead to ACS.

\section{Conclusion}

The prevalence of ACS is estimated to be $5.44 \%$. ACS in Sudanese individuals with DM was associated with hypertension, increase in age and increase in duration of DM. Treatment of hypertension and optimization of DM control are important and cost-effective ways for reducing the prevalence of ACS in individuals with DM and should be advocated by the health authorities and the public in Sudan.

\section{Financial Support}

Health Insurance Corporation, Khartoum state (HIKS), Sudan and Patients Helping Fund, Khartoum, Sudan.

\section{Conflict of Interest}

There is no conflict of interest.

\section{References}

1. Noor SK, Elmadhoun WM, Bushara SO, Ahmed MH. The Changing Pattern of Hospital Admission to Medical Wards: Burden of non-communicable diseases at a hospital in a developing country. Sultan Qaboos Univ Med J. 2015;15(4):e517-522.
2. Elmadhoun WM, Noor SK, Ibrahim AA, Bushara SO, Ahmed MH. Prevalence of diabetes mellitus and its risk factors in urban communities of north Sudan: Populationbased study. J Diabetes. 2016;8(6):839-846.

3. Noor SK, Bushara SO, Sulaiman AA, Elmadhoun WM, Ahmed MH. Undiagnosed diabetes mellitus in rural communities in Sudan: prevalence and risk factors. East Mediterr Health J. 2015;21(3):164-170.

4. Ahmed MH, Ali YA, Awadalla H, Elmadhoun WM, Noor SK, Almobarak AO. Prevalence and trends of obesity among adult Sudanese individuals: Population based study. Diabetes Metab Syndr. 2017.

5. Ali YA, Almobarak AO, Awadalla H, Elmadhoun WM, Ahmed MH. Obesity among Sudanese adults with diabetes: a population-based survey. Ann Transl Med. 2017;5(12):252.

6. Noor SK, Elmadhoun WM, Bushara SO, Almobarak AO, Salim RS, Forawi SA, Awadallah H, et al. Glycaemic control in Sudanese individuals with type 2 diabetes: Population based study. Diabetes Metab Syndr. 2016.

7. Almobarak AO, Barakat S, Suliman EA, Elmadhoun WM, Mohamed NA, Abobaker IO, Noor SK, et al. Prevalence of and predictive factors for nonalcoholic fatty liver disease in Sudanese individuals with type 2 diabetes: Is metabolic syndrome the culprit? Arab J Gastroenterol. 2015;16(2):54-58.

8. Almobarak AO, Barakat $\mathrm{S}$, Khalifa $\mathrm{MH}$, Elhoweris $\mathrm{MH}$, Elhassan TM, Ahmed MH. Non alcoholic fatty liver disease (NAFLD) in a Sudanese population: What is the prevalence and risk factors? Arab J Gastroenterol. 2014;15(1):12-15.

9. Khalil S, Almobarak AO, Awadalla H, Elmadhoun WM, Noor SK, Sulaiman AA, Ahmed MH. Low levels of physical activity in Sudanese individuals with some features of metabolic syndrome: Population based study. Diabetes Metab Syndr. 2017.

10. Awadalla H, Noor SK, Elmadhoun WM, Almobarak AO, Elmak NE, Abdelaziz SI, Sulaiman AA, et al. Diabetes complications in Sudanese individuals with type 2 diabetes: Overlooked problems in sub-Saharan Africa? Diabetes Metab Syndr. 2017.

11. Almobarak AO, Awadalla H, Osman M, Ahmed MH. Prevalence of diabetic foot ulceration and associated risk factors: an old and still major public health problem in Khartoum, Sudan? Ann Transl Med. 2017;5(17):340.

12. Elwali ES, Almobarak AO, Hassan MA, Mahmooud AA, Awadalla H, Ahmed MH. Frequency of diabetic retinopathy and associated risk factors in Khartoum, Sudan: population based study. Int J Ophthalmol. 2017;10(6):948954.

13. Ahmed MH, Elwali ES, Awadalla H, Almobarak AO. The relationship between diabetic retinopathy and nephropathy in Sudanese adult with diabetes: population based study. Diabetes Metab Syndr. 2017.

14. Khalil SI, Ibrahim-Khalil M, el Hag M, el Shafie S, Mahgoub F, Ali EN. Coronary events in Khartoum, Sudan. J Clin Epidemiol. 1996;49(9):1013-1016.

15. Ibrahim MM, Appel LJ, Rizk HH, Helmy S, Mosley J, Ashour Z, El-Aroussy W, et al. Cardiovascular risk fac- 
tors in normotensive and hypertensive Egyptians. J Hypertens. 2001;19(11):1933-1940.

16. Al-Nozha MM, Arafah MR, Al-Mazrou YY, Al-Maatouq MA, Khan NB, Khalil MZ, Al-Khadra AH, et al. Coronary artery disease in Saudi Arabia. Saudi Med J. 2004;25(9):1165-1171.

17. Sibai AM, Tohme RA, Saade GA, Lebanese Interventional Coronary Registry Working G. Coronary angiography in Lebanon: Use and overuse. Int J Cardiol. 2008;125(3):422-424.

18. Hertz JT, Reardon JM, Rodrigues CG, de Andrade L, Limkakeng AT, Bloomfield GS, Lynch CA. Acute myocardial infarction in sub-Saharan Africa: the need for data. PLoS One. 2014;9(5):e96688.

19. Onen CL. Epidemiology of ischaemic heart disease in sub-Saharan Africa. Cardiovasc J Afr. 2013;24(2):34-42.

20. Ahmed AM, Ahmed NH, Abdella ME. Pattern of hospital mortality among diabetic patients in Sudan. Practical Diabetes Int. 2000;17:41-43.

21. Suliman A. The state of heart disease in Sudan. Cardiovasc J Afr. 2011;22(4):191-196.

22. Bushara SO, Noor SK, Ibraheem AA, Elmadhoun WM, Ahmed MH. Prevalence of and risk factors for hypertension among urban communities of North Sudan: Detecting a silent killer. J Family Med Prim Care. 2016;5(3):605610.
23. Bushara SO, Noor SK, Elmadhoun WM, Sulaiman AA, Ahmed MH. Undiagnosed hypertension in a rural community in Sudan and association with some features of the metabolic syndrome: how serious is the situation? Ren Fail. 2015;37(6):1022-1026.

24. Balla SA, Abdalla AA, Elmukashfi TA, Ahmed HA. Hypertension among rural population in four states: Sudan 2012. Glob J Health Sci. 2014;6(3):206-212.

25. Noor SK, Elsugud NA, Bushara SO, Elmadhoun WM, Ahmed MH. High prevalence of hypertension among an ethnic group in Sudan: implications for prevention. Ren Fail. 2016;38(3):352-356.

26. Balogun WO, Salako BL. Co-occurrence of diabetes and hypertension: pattern and factors associated with order of diagnosis among nigerians. Ann Ib Postgrad Med. 2011;9(2):89-93.

27. Cheung BM. The hypertension-diabetes continuum. J Cardiovasc Pharmacol. 2010;55(4):333-339.

28. Cheung BM, Li C. Diabetes and hypertension: is there a common metabolic pathway? Curr Atheroscler Rep. 2012;14(2):160-166.

29. Seedat YK. Hypertension in developing nations in subSaharan Africa. J Hum Hypertens. 2000;14(10-11):739747.

30. Opie LH, Seedat YK. Hypertension in sub-Saharan African populations. Circulation. 2005;112(23):3562-3568. 